\title{
EM FOCO
}

\section{TRANSDRAMATURGIAS NAS ARTES DO CORPO NO JAPÃO}

TRANSDRAMATURGIES IN THE BODY ARTS OF JAPAN

TRANSDRAMATURGIAS EN LAS ARTES DEL CUERPO EN JAPÓN

CHRISTINE GREINER

BEATRIZ YUMI AOKI 


\section{RESUMO}

A última década tem sido marcada por discussões que repensam a noção de dramaturgia a partir do surgimento de novas tecnologias e debates políticos. No Japão, até os anos 1990, este termo nunca havia sido amplamente usado, a não ser para obras concebidas por artistas Ocidentais. Entretanto, isso não significa que não exista uma dramaturgia nas experiências artísticas japonesas. Trata-se de uma epistemologia distinta para lidar com as relações entre texto e ação e, por isso, pede por outras abordagens. A proposta deste artigo é testar o termo transdramaturgia, tendo em vista buscar uma aproximação com alguns dispositivos lógico-afetivos identificados em experiências de artistas japoneses. Não se trata de impor uma nova classificação, mas sim, de chamar a atenção para uma lógica trans (não dicotômica), que evidencia como o processo dramatúrgico tem início antes da organização da cena artística (narrativas e gestos), durante a gênese de um pensar/ sentir corpos e ambientes. Partimos de performances transgênero que desafiam a dicotomia masculino/feminino desde o Japão medieval; e de experimentos transdimensionais recentes, que negligenciam dicotomias entre real e ficcional, pessoa e objeto, radicalizando a noção de criação como insurgência de novos sentidos para a arte. Busca-se, assim, ampliar os debates sobre dramaturgia contemporânea.

\section{Palavras-chave:} transdramaturgia; performance transgênero; transdimensionalidade; artes do corpo no Japão.

\section{ABSTRACT}

The last decade has been marked by discussions that rethink the notion of dramaturgy from the emergence of new technologies and political debates. In Japan, by the 1990s, this term has never been widely used, except for works designed by Western artists. However, this does not mean that there is no dramaturgy in Japanese artistic experiences. It is a distinct epistemology to deal with the relations between text and action and, therefore, asks for other approaches. The purpose of this article is to test the term transdramaturgy, in order to seek an approximation with some logical-affectivedevices identified in experiences of Japanese artists. It is not a question of imposing a new classification, but rather of drawing attention to a trans (non-dichotomous) logic, which shows how the dramaturgical process begins before the organization of the artistic scene (narratives and gestures), during the genesis of a thinking/feeling bodies and environments. We start from transgender performances that challenge the male/female dichotomy since Medieval Japan; and from recent transdimensional experiments that neglect dichotomies between real and fictional, person and object, radicalizing the notion of creation as an insurgency of new meanings for art. Thus, we seek to broaden the debates on contemporary dramaturgy.

\section{KEYWORDS:} transdramaturgy; transgender performance; transdimensionality; body arts in Japan. 


\section{RESUMEN}

La última década ha estado marcada por discusiones que replantan la noción de dramaturgia del surgimiento de nuevas tecnologías y debates políticos. En Japón, hasta los años 1990, este término nunca ha sido ampliamente utilizado, excepto para obras diseñadas por artistas occidentales. Sin embargo, esto no significa que no haya dramaturgia en las experiencias artísticas japonesas. Es una epistemología distinta para abordar las relaciones entre el texto y la acción y, por lo tanto, pide otros enfoques. El propósito de este artículo es probar el término transdramaturgia, con el fin de buscar una aproximación con algunos dispositivos de afectación lógicaidentificados en experiencias de artistas japoneses. No se trata de imponer una nueva clasificación, sino más bien de llamar la atención sobre una lógica trans (no dicotómica), que muestra cómo comienza el proceso dramatúrgico antes de la organización de la escena artística (narrativas y gestos), durante la génesis de un pensamiento /sensación de cuerpos y ambientes. Comenzamos a partir de actuaciones transgénero que desafían la dicotomía masculina/femenina desde el Japón medieval; $y$ de recientes experimentos transdimensionales que descuidan las dicotomías entre lo real y lo ficticio, persona y objeto, radicalizando la noción de creación como una insurgencia de nuevos significados para el arte. Por lo tanto, buscamos ampliar los debates sobre la dramaturgia contemporánea.
Palabras clave: transdramaturgia; performance transgénero; transdimensionalidad; artes corporales en Japón. 


\section{INTRODUĢ $\tilde{A} O$}

HAVIA dUAS DERIVAÇõES de dramaturgia na Grécia antiga: drama-t-ourgos (a composição do drama) e drama-t-ergon (a ação do drama). Segundo o dramaturgo e estudioso de cultura grega clássica Paul Monaghan (2014), na prática, os gregos não se preocupavam muito com essas derivações; e, como sabemos, com o passar dos séculos, a definição que se tornou referência no Ocidente foi a de um ofício para elaborar textos teatrais.

Entre as décadas de 1980-1990, os debates sobre dramaturgia da dança - conduzidos inicialmente na Bélgica e depois nos Estados Unidos, na Alemanha e na Inglaterra ${ }^{1}$ - ampliaram, significativamente, as possibilidades, reconhecendo uma dramaturgia que emergia do corpo e do movimento, sem alimentar a primazia da linguagem verbal. Outro fator que ativou o surgimento de novas concepções de dramaturgia foi o fortalecimento do campo de estudos da performance, com debates em torno da noção de performativo proposta por John Austin (1962), para quem a palavra já era uma ação; e por Judith Butler (2003) que, a partir do próprio Austin, de Michel Foucault e outros autores, politizou a noção de performatividade ou ação performativa para redimensionar os estudos de gênero, da violência e da constituição dos sujeitos.

10 número 31 da revista belga Nouvelles de Danse (1997) foi uma das primeiras publicações relevantes, trazendo artigos que mudaram radicalmente a visão de dramaturgia da dança. Posteriormente, foram organizados outros números especiais em torno do tema como On Dramaturgythe labor of the Question. Women \& Performance: a journal of feminist theory (2003); e On Dramaturgy. Performance Research (2009). 
Nos últimos vinte anos, surgiram ainda novas tentativas de ressignificação do 2021.1 termo dramaturgia como: modo de olhar (BLEEKER, 2003), dispositivo coreográfico de captura (LEPECKI, 2007), estratégias de um teatro pós-dramátiCo (LEHMANN, 2008), agenciamento (HANSEN; CALLISON, 2015), fisicalidade somática (BOWDITCH; CASAZZA; THORNTON, 2018), estratégia de tradução (BRANDSTETTER 2017), dramaturgia de novas mídias e materialidades. (ECKERSALL; GREHAN; SCHEER, 2017) ${ }^{2}$

É evidente que algumas dessas discussões mais recentes estão sintonizadas com o que estamos chamando de transdramaturgia a partir do contexto japonês, uma vez que, ao invés de alimentar a lógica dicotômica que separa corpo e mente, ação e palavra, cena e espectador; tais propostas questionam padrões de pensamento e classificações dadas a priori, negando assim, alguns dos dogmas mais estáveis do Ocidente. A diferença é que entre os artistas japoneses não foi preciso desfazer ou questionar dicotomias, porque estas já não se constituíam como ponto de partida, diferentemente dos autores marcados pelo cartesianismo e pelas concepções filosóficas de Aristóteles e Platão.

Antes de seguir com as análises, é importante salientar que o objetivo deste artigo não é fortalecer diferenças e/ou confrontos entre Oriente (especificamente Japão) e Ocidente, mas, ao contrário, identificar algumas singularidades nos modos de pensar e conceber arte e corpo, que destacam a importância do que poderíamos considerar como um dispositivo transdramatúrgico para lidar, não apenas com a cena artística, mas também com questões políticas e filosóficas que alimentam o fazer artístico e que estão relacionadas a tópicos cada vez mais importantes para o século XXI como, por exemplo, a aliança entre natureza e cultura. Para tanto, começaremos com alguns dados históricos para localizar a discussão.

2 Na coletânea The Routledge Companion to Dramaturgy (2015) organizada por Magda Romanska, há ainda uma multiplicidade de novas definições de dramaturgia como modos de colaborar, modos de comunicar, o dramaturgo como curador, entre muitas outras interpretações. 


\section{UMA OUTRA EPISTEMOLOGIA DO CORPO}

Nos teatros tradicionais do Japão - entre os quais destacam-se o nô, o kabuki e o bunraku - o texto nunca foi protagonista. Já nos manifestos do pioneiro Motokiyo Zeami (1363-1443), as noções de beleza, circunstância e espacialidade indicavam que a cena nô não partia de uma hierarquia entre texto, movimento, canto e imagem. A lógica ideogramática do nô, como dizia Haroldo de Campos (1969), já se instaurava como aquilo que se pode considerar uma lógica trans, que tudo atravessa e que, para Campos, inspirava processos de transcriação. O ideograma é um pictograma que nasce na escrita chinesa e fundamenta a escrita no Japão (kanji), organizando-se a partir da conexão de ideias e imagens. Assim, um traço pode mudar o significado do caractere remetendo a outra ideia. O único modo de traduzir esses pictogramas na arte, seria transcriá-los poeticamente.

Na cena nô, há um entrelaçamento entre o palco, o pinheiro pintado ao fundo, o coro de músicos, os atores em cena (shite e waki), as vestimentas (que segundo Campos lembravam parangolés uma vez que o sentido vinha do movimento do corpo), as máscaras, a dança (shimai) e o canto (utai). Em termos de treinamento, essa lógica de atravessamentos reflete-se no absoluto desinteresse dos japoneses pela separação corpo e mente, teoria e prática, materialidade e imaterialidade. O conhecimento sempre se constrói a partir do treinamento, tanto no que se diz respeito ao teatro nô, como à poesia waka ou qualquer outra arte zen. Conhecer é treinar. Uma ação que também pode ser entendida como cultivar.

Além de Zeami, entre os grandes estudiosos do corpo e, mais especificamente da questão corpo-mente no Japão, destacam-se Yasuo Yuasa (1987) e Kigen Dôgen ([1980] apud NAGATOMO, 1992). Em Yuasa (1987), pode-se até reconhecer um dualismo, mas muito distinto do cartesiano porque o dualismo em Descartes é ontologicamente disjuntivo, admitindo a não interação entre duas realidades separadas, do corpo e da mente, da matéria (res extensa) e do espírito (res cogitans). Para Yuasa (1987), há um dualismo epistemológico e provisório que se refere a noções de interioridade e exterioridade, mas que está o tempo todo mudando para um não dualismo, através da prática transformativa do autocultivo. 
A transformação, portanto, é um fato empírico que expressa a correlação entre corpo e mente e que se realiza através da práxis. O autor identifica quatro circuitos de esquema corporal e o quarto, curiosamente, é chamado de quase-corpo. Isso significa que, de fato, o corpo é sempre um quase-corpo porque nunca se apronta, nunca é algo dado, mas está sempre se transformando.

Já em Dôgen (1200-1253), o corpo humano consiste em terra, água, fogo e vento, o que significa compartilhar os mesmos elementos que constituem a natureza. Por isso, não está separado da natureza. Não se trata do ser humano e a natureza. O mundo proposto por Dôgen (1980) é intercorporal e transubjetivo ${ }^{3}$. A natureza é cultural e o somático e a consciência encarnada no corpo são a base da objetividade dos dharmas (estados da mente). O ato somático é a transformação da imagem de um corpo expandindo a afetividade que garante a vida.

Por conta dessas explicações, aqui apresentadas de maneira muito breve, torna-se evidente que a separação entre uma coisa extensa (corpo) e a mente (sem extensão corpórea), nunca fizeram sentido. Assim, também se torna irrelevante admitir um organismo biológico não cultural. Se o corpo nunca é dado e pronto, sempre se constituirá em movimento, nas ações propostas em diversos contextos.

A história das performances transgênero no Japão ampara-se, portanto, nessa mesma concepção impermanente e fluída de corpo. Inicialmente, confunde-se com a própria história do teatro japonês do século XVII e aquilo que poderia ser considerado avant la lettre uma arte queer (em japonês クイア・アート), remonta ao mesmo período e se estende por todo século XVIII, como a chamada estética da excentricidade. (BRECHER, 2013) Não se trata apenas de uma certa estranheza, mas sim, de escapar do centro, geográfico e de poder.

O artista excêntrico seria aquele capaz de inventar espaços para além das categorias dadas. O historiador da arte Tsuji Nobuo publicou um compêndio em 1968 que se tornou uma referência para estudar o tema. A sua Linhagem dos excêntricos $^{4}$ (2011) buscava entender como este movimento poderia ser observado como estética singular e fenômeno social.

3 A obra de Dôgen a qual Nagatomo se refere é Shôbôgenzô. Toquio: Iwanami shoten, 1980, volumes 1 e 2 .

4 Título original: Lineage of Eccentrics. 
Na década de 1920, estas experiências são documentadas midiaticamente e reconhecidas como parte do movimento ero-guro-nansensu (erótico, grotesco, non-sense) que produzirá filmes, publicações e performances como um modo particular de experimentar a vida. Em termos de artes visuais, a pintura considerada pioneira do ero gurofoi criada dois séculos antes por Katsushika Hokusai considerado, por sua vez, como um dos grandes nomes do excentrismo. A sua obra Takoto Ama - traduzida não literalmente como "O sonho da esposa do pescador", de 1814 - retratava um polvo cheio de tentáculos praticando sexo oral em uma mulher. Desde então, esta imagem tem instigado a imaginação de muitos artistas, como foi o caso de Aida Makoto que criou, em 1993, uma obra explicitamente inspirada pela pintura de Hokusai: The Giant Member Fuji versus King Gidora.

No Japão, a noção de gênero como uma construção em processo sempre reconheceu a materialidade corpórea como algo não substancial, ou seja, não restrita a carne, ossos, pele e músculos; mas sim, como uma rede sígnica da qual emergem subjetividades. ${ }^{5}$

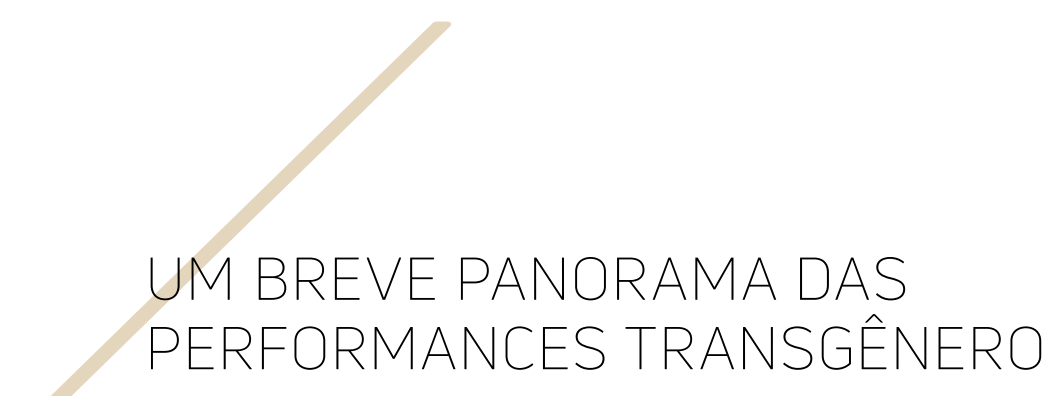

É provável que a primeira performance transgênero no Japão tenha acontecido em torno de 1603 em Quioto, quando a dançarina e sacerdotisa Izumo no Okuni concebeu a primeira versão do teatro kabuki (onna no kabuki ou kabuki de mulheres). Vestida com trajes masculinos, Okuni misturava referências dos samurais (espadas e penteados) com túnicas de missionários cristãos. Há pouco material sobre este período com exceção de algumas gravuras e pequenos textos que falam do chamado kabukimono. Este termo era normalmente traduzido como coisas estranhas, pois referia-se a grupos que se vestiam e falavam de forma peculiar. Uma das características que os tornava subversivos era justamente o fato de os homens se travestirem de mulheres e foi assim que Okuni, inspirada por eles, decidiu se travestir de homem antecipando

5 Isso não significa, evidentemente, que as singularidades de gênero foram sempre bem-vindas no Japão. Trata-se de uma sociedade patriarcal, extremamente disciplinar e com inúmeros problemas para enfrentar as situações que subvertem os padrões de gênero aceitos socialmente. No entanto, há ambivalências que muitas vezes escapam aos juízos de valor. Nota-se, por exemplo, que o termo homossexualidade só chega ao Japão a partir da era Meiji (18681912) quando o país abre oficialmente as suas portas ao Ocidente. Antes disso, a prática não era nomeada, o que sugere uma curiosa irrelevância, a despeito dos preceitos morais que passaram a imperar a partir do século XX. (MCLELLAND; MACKIE, 2015) 
em alguns séculos o que poderia ser considerada uma performance transgênero. (MILLER; BARDSLEY, 2005)

Mais do que um figurino, é importante notar que o travestimento de Okuni questionava a soberania masculina na vida cotidiana. Parodiar, tanto os samurais quanto os missionários, implicava em criticar o poder masculino dentro e fora do Japão.

Após ter sido censurada e acusada de prostituição, Okuni e suas dançarinas foram banidas da cena teatral. O kabuki passará por diversas fases e a versão que ficou internacionalmente conhecida até hoje, trará à cena os atores onnagata especializados na personificação de mulheres.

É importante notar que, além da maquiagem e dos trajes de gueixa, esses atores passam por um treinamento longo e rigoroso. Mais do que os adereços é a corporificação do gesto feminino que constitui o ponto crucial da performance. Não há nenhum tipo de partitura psicológica ou perfil a ser construído. Desde muito jovens, os atores iniciam o treinamento corporal transcriando movimentos, como por exemplo, os gestos idealizados de mulheres do período Edo ou Tokugawa (1603-1867). É através desse modo particular de testar uma mimese imaginária, conhecida como monomane (KUSANO, 1993), que se constrói a imagem e o corpo transgênero.

Outro artifício bastante utilizado é o mitate que seria um sistema de representação imaginária que opera através de transporte ou metáfora, ou seja, algo que fica no lugar de outro. Assim, o corpo transgênero do onnagata não é propriamente uma mulher, nem tampouco um homem representando uma mulher, mas um terceiro, uma representação imaginária que não é nem um nem outro, mas ambos. A chave está na ambivalência e não na dicotomia, assim como na transdramaturgia proposta na constituição de um corpo que não é nem masculino, nem feminino, mas um e outro. ${ }^{6}$

Como se fosse uma espécie de experiência antípoda ao kabuki, o teatro de revista Takarazuka estreou em 1914, concebido por Ichizo Kobayashi na cidade com o mesmo nome, localizada nas proximidades de Osaka. Ao contrário do que ocorria no kabuki, na companhia Takarazuka eram as mulheres que personificavam os

6 Há pesquisas curiosas que relatam o fato de alguns atores onnagata terem sintomas da menopausa a partir da meia-idade, uma vez que viviam as personagens em tempo integral. Apenas muito recentemente, tornou-se possível para os atores de kabuki se casarem e ter família, desde que a vida pessoal para não contamine o olhar do público. (LEITER, 2002) 
papéis masculinos (otokoyaku). Vários autores consideram essa experiência o primeiro grande sucesso de massa no Japão. Uma experiência teatral e fenômeno comunicacional que não chega a colaborar de maneira efetiva com as questões dramatúrgicas, a não ser no que se refere ao seu aspecto mais comercial. ${ }^{7}$

Se algumas questões de gênero já podiam ser observadas tanto no onnagatacomo no otokoyaku, é nos anos 1980 que emerge uma problematização política explícita a partir de imagens transgênero na conexão entre artes visuais e performance para pensar a alteridade, a sexualidade e uma série de questionamentos que vão surgindo nos confrontos e possíveis diálogos entre Oriente e Ocidente. Trata-se de Yasumasa Morimura. (KHAN, 2007)

A partir de 1988, com Self-portrait as Art History, Morimura criou uma série de autorretratos sobrepostos a pinturas canônicas ocidentais como a Olympia de Manet, Monalisa de Leonardo da Vinci, entre outras. Em seguida, usou a mesma estratégia na série Self-portrait as actress e para realizar estes ensaios fotográficos, criou figurinos, maquiagem, cenários e gestos que compuseram as fotomontagens.

O termo japonês para esta série fotográfica era futago que poderia ser traduzido como gêmeos, no sentido de mesclar homem e mulher, branco e nãobranco, cópia e original, obras de arte e mídia. Como o próprio Morimura afirmou em diversas ocasiões, uma de suas fontes de inspiração foi a obra da artista Cindy Sherman, especialmente Untitle Film Stills do final dos anos 1970. Morimura foi encontrando um modo bastante peculiar de criar, como é evidenciado em AnInner Dialogue with Frida Kahlo (Four Parrots) de 2001. Não se trata apenas de imitar a postura de Kahlo com seus adereços, mas de testar aquilo que no âmbito da performance será formulado como um reenactement, do modo como Rebecca Schneider (2011) tem discutido. É como se a imagem/pensamento/movimento do outro fosse internalizada provocando um devir outro ou o ser tomado pela diferença para se reconstituir.

De certa forma, essa estratégia não é absolutamente distinta do monomane do kabuki que, ao partir da mimese imaginária, não se restringia à cópia de um modelo. O internalizar do sistema imaginativo idealizado de feminilidade acionava um devir-feminino e uma transdramaturgia entre corpo e imagem, homem e mulher, imagem e movimento. 
Desde os anos 1980, foram surgindo, pouco a pouco, mudanças políticas relativas

às questões de gênero no Japão. Um dos grupos artísticos mais ativistas desta época foi a companhia Dumb Type, criada em 1984 por estudantes da Universidade de Quioto. O diretor Teiji Furuhashi morreu de AIDS em 1995 e, durante os dez anos em que esteve à frente do grupo, fez questão de problematizar de maneira bastante incisiva as relações de poder existentes na cultura japonesa. As suas obras pH e S/N, respectivamente de 1990 e 1994, trouxeram questões importantes em um momento em que os debates sexuais, o tema do capitalismo e a mercantilização do corpo não eram ainda explicitadas. (HATANAKA;TAKADA; SHIBA, 2002)

Uma experiência mais recente que, de certa forma, repropõe algumas discussões em torno da performancetransgênero é o solo About Kazuo Ohno do coreógrafo Takao Kawaguchi, que começou a ser concebido em 2013, tendo sido apresentado em diversos países desde então, inclusive no Brasil, no Sesc Campinas, em 2018. Kazuo Ohno (1906-2010) apresentou três solos dirigidos pelo criador do butô Tatsumi Hijikata (1928-1986), respectivamente em 1977, Admiringla Argentina (Admirando la Argentina), em 1981 My Mother (Minha Mãe) e, em 1985 Dead Sea (Mar Morto). Em todos estes trabalhos, havia uma lógica trans - um devir la Argentina, devir mãe - e um transitar entre mundos distintos - mundo dos vivos, mundo dos mortos.

Ao iniciar o processo de criação testando estratégias de monomane e mitate em relação aos movimentos e imagens de Ohno, a partir de filmes e fotografias; Kawaguchi propôs eliminar de seus estudos todo tipo de especulação sentimental e/ou transcendental que costuma pairar em torno deste grande mestre. Optou por focar especificamente na constituição dos movimentos e imagens do corpo de homem transcriado em corpo de mulher e recapturado novamente por um corpo de homem, desta vez bem menos franzino e frágil. A sua principal questão foi como acionar o processo de reenactment a partir da defasagem radical de si mesmo. ${ }^{8}$

8 Kawaguchi dançou com o grupo DumbType de 1996 a 2008, vivenciando a efervescência do ativismo presente nas performances do grupo. Este foi também o momento do nascimento das festas drag com o sloganDiamonds are forever. (MCALLISTER, 2017) Um pouco antes, em 1994, a X Conferência sobre AIDS de Yokohama, reuniu ativistas que lutavam pela diversidade de gêneros e direitos iguais para todas as pessoas. Na ocasião, criaram uma frase que seria o acrônimo de AIDS "And I Dance with Somebody", com uma tradução livre de " $E$ eu danço com alguém". 


\section{APERFORMANCENOS DEBATESPOLITICOS}

No Ocidente, os estudos de gênero foram marcados pelos livros de Simone de Beauvoir O segundo sexo (2008) e de Judith Butler Problemas de gênero: feminismo e a subversão da Identidade (2003) e, mais recentemente, pelo Manifesto contrassexual: práticas subversivas de identidade (2000) de Paul B. Preciado, entre muitos outros nomes fundamentais que, com a proliferação dos programas e centros de estudos de gênero nas universidades, congressos e seminários, fortaleceram os debates.

Na Ásia, a indiana Gayatri C. Spivak foi uma das pioneiras publicando o ensaio Pode o subalterno falar? Especulações sobre o sacrifício das viúvas (1985). Pouco depois, a vietnamita Trinh T. Minh-ha lança Woman, Native, Other. Writing post coloniality and feminism (1989). As duas foram, de certa forma, referências iniciais para os debates de gênero e política na Ásia. No Japão, embora o feminismo e as lutas políticas existissem desde 1870 até as décadas de 1920 e 30 - quando a grande questão era o sufrágio. O fortalecimento dos debates e publicações ocorre apenas a partir de 1970. A exceção foi a revista Seitō cujo nome havia sido inspirado pela sociedade inglesa Bluestocking. (LÉVY, 2012) ${ }^{9}$

Na geração pós 1970, um dos nomes mais importantes do ativismo de gênero no Japão é o de Kazuko Takemura que, além de traduzir Spivak, Butler e Trinh T. Minh-ha, reuniu pesquisadoras e ativistas japonesas. (SHIGEMATSU, 2012)

Simultaneamente aos debates teóricos e à construção desse campo de pesquisa, muitos grupos de mulheres começaram a se organizar como foi o caso das Tatakau Onnatachi (Mulheres que lutam ou Mulheres Lutadoras). Elas faziam parte do movimento de libertação e assumiam a insatisfação diante da posição dos homens da chamada nova esquerda. Ao que tudo indicava, lutar por melhores condições de trabalho não incluía a luta das mulheres que continuavam ocupando uma posição de subserviência e invisibilidade. (MC CARTHY, 2010)
9 Publicada a partir de 1910, essa revista trazia inúmeros debates sobre sexualidade, prostituição, aborto e direitos humanos. As jornalistas que compunham a redação questionavam a máxima confucionista patriarcal das "boas mães, sábias mães" que ainda imperava no Japão. A editora Raichō Hiratsuka foi considerada uma das pioneiras do ativismo feminino no Japão, em seguida, substituída pela anarquista Noeltō, que ocupou o cargo de editora radicalizando a posição da revista e acabou sendo brutalmente assassinada aos 28 anos, ao lado do companheiro e de um sobrinho. (HANE, 1982) 
Não cabe aqui esmiuçar os movimentos feministas e as lutas que ocorreram 2021.1

desde então. No entanto, é importante notar que as artistas mulheres passaram a estar cada vez mais presentes em cena, não apenas como atrizes e dançarinas, mas como coreógrafas, diretoras e performers ativistas. Grupos como Yubiwa Hotel, Nibroll e Cathy instauraram mudanças na cena contemporânea japonesa e discussões políticas para pensar o corpo feminino, as relações de poder e as mudanças radicais na chamada cultura girly ou cultura das garotas. (ANAN, 2016)

Há uma bibliografia considerável sobre esse ativismo feminino nas artes do corpo, mas ainda pouco se fala sobre como a performancetransgênero colaborou com esses debates, destacando as identidades em processo como parte da própria concepção de corpo e sexualidade no Japão; e fortalecendo as transdramaturgias.

O cotidiano no Japão é recheado de códigos de conduta moralistas em ambientes corporativos e institucionais, pautados por padrões aceitos socialmente. Ao mesmo tempo, a moda urbana, a cultura pop (música, games etc.) e a multiplicidade de cenas artísticas lidam com a transgeneridade de maneira pouco convencional aos olhos ocidentais. Neste sentido, parece insuficiente usar apenas os autores europeus e americanos para analisar as performances transgênero no Japão. É necessário testar outras epistemologias locais bem como provenientes daquilo que se constitui fora do mundo não ocidental (ou seja, centro Europa e América do Norte). ${ }^{10}$

Talvez a transdramaturgia seja, justamente, uma estratégia epistemológica para lidar com as culturas cujo paradigma de concepção inicial do corpo não é cartesiano e, portanto, não separa corpo e mente, natureza e cultura. A negação da representação nunca se colocou como uma questão nestes contextos, nos quais a potência política das performances não está em representar o outro, mas em desestabilizar a si mesmo a partir da internalização da outridade.

10 Há uma entrevista realizada com Michel Foucault pelo diretor de teatro Shūji Terayama, "O Saber como Crime", incluída no volume VII dos Ditose Escritos de Foucault. Ver: Motta (2011). Nela, Foucault discorda veementemente de Terayama quando este afirma que a história é teatro. 0 argumento de Foucault é que não existem espectadores para a história. A dificuldade de Terayama para compreender o seu argumento é que na sua prática teatral não havia espectadores, todos de certa forma participavam e seguiam fabulando os acontecimentos em suas imaginações. 


\section{CORPOS TRANSDIMENSIONAIS}

Outro exemplo no contexto das artes do corpo no Japão que lida com o que estamos chamando de transdramaturgias é o das chamadas transdimensionalidades que emergem com o surgimento de novas tecnologias, relacionadas à robótica, ao surgimento das vocalóides e hologramas. Antes de falar especificamente das experiências artísticas é importante compreender o contexto no qual foram geradas.

No cenário japonês, entende-se que o interesse pelos robôs surge por volta do século XVII com os karakuriningyō. Em linhas gerais, Karakuri teria como significado "mecanismo" ou "truque", fazendo referência a um instrumento feito com o intuito de enganar, iludir ou surpreender uma pessoa.

A palavra ningyō (人形) significa boneco, fantoche, sendo composta pelos ideogramas de pessoa (人) e forma (形) (em tradução literal, se referiria a algo com a forma de uma pessoa).

Feitos de madeira, os bonecos são desenvolvidos artesanalmente por mestres karakuri, produzidos com a finalidade de entretenimento. A movimentação parte de seu mecanismo interno com dispositivos mecânicos como molas, água e areia; por cordas e pedaços de madeira, como as marionetes; ou, ainda, de forma autômata (e, assim, independente da manipulação humana, quando acionado), utilizando-se do mecanismo similar ao de um relógio.

Para Suzuki (2007 apud SONE, 2017, p. 8, grifo do autor), os karakuriningyō incorporariam uma

\footnotetext{
[...] dramaturgia do falível como estratégia de entretenimento: por exemplo, como um autômato na forma de um arqueiro que falha em atingir um alvo com sua flecha estabelece um sentimento de empatia em relação ao ‘artista’ karakuri.
} 
A tradição dos autômatos lúdicos permaneceu na cultura japonesa até o início do século XX, acompanhando o desenvolvimento de novas tecnologias.

Em 1928, o biólogo japonês Makoto Nishimura criou Gakutensoku, uma versão de um autômato moderno - considerado o primeiro robô japonês -, apresentando-o na exposição em celebração à posse do trono do imperador Hirohito. A criação consistia em um tronco equivalente ao humano, que ficava disposto sobre um altar de quase dois metros de altura. O Gakutensoku, por meio de um sistema pneumático, conseguia movimentar o rosto, olhos e braço, e apresentava expressões e gestos suaves, atraindo visitantes por meio de uma atmosfera teatral e similar a um templo.

Sone (2017) destaca a importância de analisar a popularidade dos karakuriningyō e do Gakutensoku no contexto japonês, ressaltando a diferença de entendimento entre o Japão e o Ocidente em relação aos robôs. Para o autor, “no Ocidente, a ideia de um autômato era de recriar o ser humano a partir de matéria ‘burra’, enquanto a visão japonesa é de que os humanos já são parte de uma natureza viva, e que então o robô seria parte da natureza". (SONE, 2017, p. 9) De acordo com Greiner (2015), desde as concepções mais antigas de corpo no Japão, originadas da Índia e da China, duas das noções primordiais seriam essa aliança entre natureza e cultura e a continuidade entre sujeito e objeto. Na sociedade japonesa, Sone (2017, p. 89) relaciona também a afinidade com os robôs à visão de mundo voltada ao animismo, que vê os espíritos encarnados na natureza, e à influência de doutrinas religiosas e filosóficas como o budismo e o taoísmo. Ele afirma, ainda, que os robôs ocupam um lugar especial dentro do imaginário japonês, que foge de dicotomias: “[...] não é nem humano, nem objeto”.

O autor considera os robôs “objetos performativos” (SONE, 2017), destacando um entendimento diferente do que foi desenvolvido por Butler, por exemplo. Para Sone (2017, p. 14), a discussão dos robôs refere-se a uma “[...] capacidade generativa e significante, e não a um potencial subversivo". Nesse sentido, observa como a performatividade dos eventos protagonizados por robôs japoneses (como exposições, instalações públicas, competições e interações em espaços domésticos) “[...] tem a capacidade de implicar os participantes na geração de significado por meio de sua performance em situação ou evento de palco culturalmente específico". (SONE, 2017, p. 14) 
Sone (2017) analisa também a figura do robô dentro de expressões artísticas, como as peças de teatro do dramaturgo e diretor Oriza Hirata produzidas com androides criados pelo roboticista Hiroshi Ishiguro. A parceria rendeu produções como I, Worker (働〈私) (2008), Sayonara (2010), Three Sisters, Android Version (2013) e Metamophosis, Android Version (2014), tendo como temática a coexistência de humanos e robôs, e a possibilidade de criar laços afetivos entre eles.

Em I, Worker, a história aborda a crise existencial de um robô que se exila, tornando-se um hikikomori, um fenômeno social japonês em que as pessoas ficam reclusas em suas próprias casas. Na peça Sayonara, a personagem principal tem uma doença fatal, e seus pais deixam-na com um robô de companhia. Three Sisters, Android Version é uma adaptação da peça de Anton Chekhov (1990) e traz três irmãs que têm em sua família dois robôs - um deles em substituição à irmã mais nova, e utilizado como avatar por ela. Inspirado no texto de Kafka, Metamorphosis, Android Version foi interpretada por atores franceses, em francês, e o personagem principal, Gregor Samsa, transformava-se em androide, ao invés de inseto, como na versão original.

De forma geral, as narrativas mostram um futuro próximo no qual os robôs estão inseridos na vida cotidiana, e retratam questões sociais do Japão contemporâneo, como o isolamento, a solidão e a apatia, por meio do relacionamento entre humanos e seus robôs de companhia - revelando, assim, “[...] as complexidades e angústias da existência humana". (SONE, 2017, p. 92) De outra perspectiva, para Ishiguro, o ponto principal das peças não seria as temáticas de vida e morte, mas “[...] um campo de teste em sua busca para fazer robôs mais parecidos com humanos". (ECKERSALL; GREHAN; SCHEER, 2017, p. 118)

Além do projeto colaborativo com Hirata, Ishiguro tem desenvolvido trabalhos com seus robôs em diferentes frentes. Em 2009, ele se apresentou junto a seu gêmeo-robô, o Geminoid HI-1, no Ars Eletronica, festival internacional de artes midiáticas. No final da apresentação, o robô simulou sua morte por meio de efeitos na voz e respiração. (SONE, 2017)

Nesse sentido, há projetos como o Digital Shaman Project, da artista japonesa Etsuko Ichihara, que propõe uma nova forma de luto por meio das tecnologias 
disponíveis. Por meio de robôs vestindo máscaras impressas em 3D, equipados com programas que imitam características físicas humanas - fala, gestos, personalidade -, a artista representava pessoas já falecidas, como se os robôs estivessem possuídos por seus espíritos. O programa funciona por 49 dias após a morte de determinado indivíduo - período tradicional de luto de acordo com o budismo -, permitindo que a família ou pessoas próximas possam ter conversas e usar o tempo para se despedir. No $49^{\circ}$ dia, o robô se despede e o programa é encerrado.

Partindo de reflexões sobre a morte - seja de humanos, robôs ou hologramas, a ópera em holograma The End, protagonizada pela cantora virtual Hatsune Miku e produzida em colaboração entre o músico Keiichiro Shibuya, o diretor e roteirista Toshiki Okada e o ilustrador YKBX, trazia como pontos centrais o significado da morte e o paradoxo da existência da cantora.

Hatsune Miku (初音ミク), ou “o primeiro som do futuro”, em tradução livre, é uma personagem criada para um software de sintetização de voz chamado Vocaloid, que permite que o usuário insira letras de músicas e adicione notas musicais e efeitos vocais, para que o próprio sistema construa uma canção. Em 2009, ela realizou seu primeiro show ao vivo para um público de 25 mil pessoas no festival Animelo Summer Live, realizado na cidade de Saitama, no Japão. O que diferencia Miku de outras celebridades japonesas é o fato de que ela não é uma pessoa, mas uma imagem, um holograma, um ídolo virtual. Miku se apresenta por meio de shows holográficos, tendo realizado turnês pela Ásia, América do Norte e Europa.

Outras performances incluem a participação em concertos com a NHK Symphony Orchestra e a Tokyo Philharmonic Orchestra, o projeto multimídia Still Be Here, concebido pela musicista e compositora Laurel Halo, em parceria com outros quatro artistas. Apresentado pela primeira vez em Berlim, na Alemanha, o espetáculo passou também por Áustria e Inglaterra, tendo como temática a desconstrução de um pop star no século XXI, em questões de gênero, fãs, desejo e identidade. Ainda, em 2017, HatsuneMiku fez uma apresentação especial com o grupo de taikô Kodō. 


\section{CONSIDERAÇÕES FINAIS}

O modo como as transdramaturgias instauram agenciamentos entre as esferas do animado e do inanimado é marcado por uma desierarquização radical, ou seja, o ser humano não é necessariamente mais importante do que todos os outros seres e objetos. O que se chama de transdimensionalidade no Japão, refere-se, justamente, à possibilidade de trocas e relacionamentos (inclusive afetivos) entre pessoas e hologramas, pessoas e robôs, pessoas e personagens. Admite-se um atravessamento entre realidades supostamente pertencentes a diferentes dimensões. ${ }^{11}$

No Japão, essas experiências não emergem apenas dos debates instaurados pelas novas tecnologias, mas remetem aos teatros de bonecos, entre os quais, 0 bunraku é um dos gêneros mais conhecidos desde o século XVII. Nos teatros de bonecos já não havia um protagonismo dos seres humanos, mas uma indistinção entre os movimentos dos corpos dos manipuladores e dos bonecos. No que diz respeito ao transdimensional pode-se pensar também no modo como o teatro nô admitia o relacionamento entre pessoas e fantasmas, sem nenhuma dificuldade. ${ }^{12}$

A partir da crise instaurada pela Covid-19, as experiências artîsticas que lidam com as transdramaturgias e a investigação de novas materialidades tornou-se mais intensa. Artistas da cena contemporânea japonesa como o diretor de teatro Toshiki Okada e a artista da dança Satoko Ichihara têm proposto ações que lidam com o ambiente digital não apenas como uma mídia para transmissão das mesmas experiências realizadas anteriormente de maneira presencial, mas de modo a agenciar novas concepções de corpo, arte e comunicação com o público.

No caso de Okada, ele partiu de sua obra Eraser Mountain, inspirada pela obra de Timothy Morton (2008) e repensou a proposta desta peça para uma versão na plataforma ZOOM chamando-a de Eraser Fields. ${ }^{13}$ Em colaboração com o artista visual Teppei Kaneuji, a proposta foi indagar como estabelecer uma paisagem igualitária incluindo materiais, projeções, performers e sons. Tudo começa quando uma máquina de lavar quebra e parece não ter mais nenhuma utilidade. Os performers desaparecem entre os objetos. Privados das suas conexões com a vida
11 No Japão, há casamentos entre pessoas e hologramas de personagens de animês, por exemplo. Em 2009 foi realizada a primeira cerimônia de casamento informal entre um homem e uma personagem de videogame e, em 2017, a desenvolvedora de jogos Hibiki Works ofereceu ao público japonês a realização de uma cerimônia de casamento em realidade virtual com personagens de um jogo. No final de 2018 , o japonês Akihiko Kondo realizou a cerimônia de seu casamento com a ídolo virtual Hatsune Miku.

12 O cineasta Kenji Mizoguchi apresentou de maneira brilhante a continuidade entre imagens da vida cotidiana e seus fantasmas no filme Contos da Lua Vaga (1953), em uma das suas famosas sequencias sem cortes, quando apresenta uma personagem sedutora caracterizada como atriz de nô.

13 A estreia está disponível no YouTube. Ver: https://www.youtube. $\mathrm{com} /$ watch?v=NF96_ $k Z e U 1 c \& t=1224 s$. Ver também: https:// www.youtube.com/ watch?v=FiJdIHUMjeQ 
cotidiana, tudo é revirado e mesmo as noções de espaço e tempo não são mais concebidas pela perspectiva humana.

Essa pesquisa de Okada com Kaneuiji gerou também o chamado Eizo Theater, que abriga o projeto Beach, Eyelids, and Curtains, composto por seis vídeos-peças desenvolvidas com o designer de vídeo Shimpei Yamada. A proposta foi explorar a experiência sensória, a partir do que acontece ao se lidar com o formato de projeção de imagens. Okada imaginou pistas para refletir sobre as conotações de fronteiras, linhas e paredes. ${ }^{14}$

Quanto à Satoko Ichihara, o seu foco de pesquisa é pensar como fugir dos padrões e das concepções pré-estabelecidas. Logo no início da pandemia, decidiu recriar a sua obra The Problem of Faeries $(2017)^{15}$ para uma performance veiculada também no ZOOM, ao vivo. Ela seguiu o texto pré-existente, mas ao invés de apresentar um solo como na versão original, propôs uma colaboração com várias atrizes, cada qual participando em suas respectivas próprias casas. Ichihara problematiza a questão da eugenia e a escolha deliberada e autoritária de que alguns devem morrer em detrimento de outros que seguem os padrões sociais aceitáveis de beleza e saúde. Essa obra é organizada em três partes, a primeira seguindo o modelo rakugo (estilo de contar histórias), a segunda como musical que fala sobre um casal pobre que vive rodeado de insetos e um dia usa um inseticida, descobrindo que alguns insetos “deficientes” eram imunes ao produto. E, finalmente, a terceira parte tem o formato de um seminário sobre uma bactéria que vive na flora vaginal das mulheres, o que levou a performer a pensar no valor da vida humana a partir do momento em que se aceita a presença das bactérias como parte da vida.

Concluímos, a partir dessas experiências que, a despeito das singularidades das propostas transdramatúrgicas dos artistas mencionados, o ponto comum é uma concepção fluída de corpo que se afirma nas discussões de gênero como pontuamos lembrando as estratégias ou dispositivos transdramatúrgicos desde o teatro kabuki, entre os quais destaca-se o monomane e o mitate; até as experiências mais recentes transdimensionais que se constituem no fluxo entre humanos e não humanos, realidades e ficções, reafirmando uma concepção não substantiva e, portanto, não cartesiana de corpos e sujeitos. 
O que a transdramaturgia ou os dispositivos transdramatúrgicos fazem é explicitar

processos político-afetivos que têm início antes da concepção da cena artística, propriamente dita, nos modos como se dá a emergência de subjetividades no fluxo entre corpos e ambientes, individualidades e coletivos.

\section{REFERÊNCIAS}

ADOLPHE, J.-M. (ed.). Nouvelles de Danse. Bruxelas: Contredanse, n. 31,1997.

ANAN, N.Contemporary Japanese Woman Theater and Visual Arts - Performing Girls'

Aesthetics. New York: Palgrave Macmillan, 2016.

AUSTIN, J.How to do things with words. Cambridge: Harvard University Press,1962.

BEAUVOIR, S. O Segundo Sexo. Rio de Janeiro: Nova Fronteira, 2008.

BLEEKER, M. Dramaturgy as a mode of looking. Women \& Performance: a journal of femininst theory, New York, v. 13, n. 2, p. 163-172, 2008.

BOWDITCH, R.; CASAZZA, J.; THORNTON, A. (ed.). Physical Dramaturgy: perspectives from the field. New York: Routledge, 2018.

BRANDSTETTER, G.; HARTUNG, H. Moving (across) borders. Performing Translation, Intervention, Participation. New York: Columbia University Press, 2017.

BRECHER, W. P. The Aesthetics of Strangeness, Eccentricity and Madness in Early Modern Japan. Honolulu: University of Hawaii Press, 2013.

BRIZELL C.; LEPECKI, A. (ed.). On Dramaturgy, the labor of the Question. Women \& Performance: a journal of feminist theory, New York, v. 13, n. 2, p. 15-16, 2003.

BUTLER, J. Problemas de Gênero, Feminismo e Subversão da Identidade. São Paulo: Civilização Brasileira, 2003.

CAMPOS, H. A arte no horizonte do provável. São Paulo: Ed. Perspectiva, 1969.

DIGITAL Shaman Project.Starts Prize, Austria, 2018. Disponivel em: https://starts-prize.aec.at/ en/digital-shaman-project/. Acesso em: 10 jul. 2020.

DÔGEN, E. Shôbôgenzô. Toquio: Iwanami shoten, 1980. v. 1.

DÔGEN, E. Shôbôgenzô. Toquio: Iwanami shoten, 1980. v. 2.

DUTCH National. Opera \&Ballet, [s. I.], [2014]. Disponivel em: http://www.operaballet.nl/en/ doublebill/2014-2015/show/end. Acesso em: 4 jul. 2020.

ECKERSALL, P.; GREHAN, H.; SCHEER, E. (ed.). New Media Dramaturgy, Performance, Media and New-Materialisms. New York: Palgrave MacMillan, 2017. 
GLOBAL star HatsuneMiku's first pop opera. The endkeiichiroshibuya + hatsunemiku. Holland

Festival, [s. I.], 2015. Disponível em: https://www.hollandfestival.nl/en/program/2015/the-end/. Acesso em: 30 jul. 2020.

GREINER, C. Leituras do corpo no Japão - e suas diásporas cognitivas. São Paulo: N-1 Ed., 2015. GRITZNER,K.; PRIMAVESI, P.; ROMS, H. (ed.). On Dramaturgy. Performance Research. London: Routledge, 2009. v. 14, n. 3.

HANE, M. Peasants, Rebels, Women and Outcastes. Londres: Rowman \& Littlefield Publishers, 1982.

HANSEN, P.; CALLISON, D. (ed.). Dance Dramaturgy Modes of Agency, Awareness and Engagement. New York: Palgrave MacMillan, 2015.

HATANAKA, M.; TAKADA,A.; SHIBA,S. Dumbtype Voyages. Tóquio: NTT Publishing, 2002.

HATSUNE Miku x Kodo Rehearsals on Sado by Yuki Hirata. KODO, [s. I.], 24 maio 2018. Disponível em: http://www.kodo.or.jp/en/tag/hatsune-miku. Acesso em: 4j ul. 2020.

KARAKURI NINGYO. [S. I.], 2008. Disponível em: karakuri.info. Acesso em: 16 jul. 2020.

KHAN, D. M. Questions of Cultural Identity and Difference I n the work of Yasumasa Morimura, Mariko Mori and Takashi Murakami. 2007. Thesis(Master of Arts in Art History) - Universidade Canterbury, Canterbury, 2007.

KUSANO, D. Os Teatros Bunraku e Kabuki: uma visada barroca. São Paulo: Perspectiva, 1993.

KYUNG, L. Tokyo man marries videogame character. CNN, [s. I.], 17 dez.2009. Disponível em: http://edition.cnn.com/2009/WORLD/asiapcf/12/16/japan.virtual.wedding/. Acesso em: 26 jul. 2020 .

LEPECKI, A .Choreography as Apparatus of Capture.TDR: The Drama Review, Cambridge, v. 51, n. 2, p. 119-123, 2007.

LEHMANN, H.-T. Teatro Pós-Dramático. São Paulo: Cosac \& Naify, 2008.

LEITER, S. A Kabuki Reader, History and Performance. New York: M.E. Sharpe, 2002.

LÉVY, C. Naissance d'une revue féministe au Japon: seitô (1911-1916), Ebisu, études japonaises 48. Paris: CNRS, 2012.

LOO, E..HatsuneMiku Virtual Idol Performs Live Before 25,000. Anime News Network, [s. I.], 23 ago. 2009. Disponível em: http://www.animenewsnetwork.com/news/2009-08-23/hatsunemiku-virtual-idol-performs-live-before-25000. Acesso em: 2 jul. 2020.

MONAGHAN, P. ‘Dramaturgies and the Dramaturg’. In: ECKERSALL, P.; MONAGHAN, P.; BEDDIE, M.(ed.). The Dramaturgies Project. [S. I.]: Real Time Arts, 2014. p. 25. Disponivel em: http://www. realtimearts.net/article/96/984. Acesso em: 2 abr. 2020.

MORTON, T. Ecology without Nature, Rethinking Environmental Aesthetics. Cambridge: Harvard University Press, 2008.

MC CARTHY, E. Ethics Embodied, rethinking selfhood through Continental, Japanese, and feminist philosophies. Londres: Rowman \& Littlefield Publishers, 2010.

MCALLISTER, N.B. Drag and Female Impersonation in Japan and in the United States. Thesis (Master of Languages and Civilizations) - University of Colorado, Colorado, 2017. 
MCLELLAND, M.; ROMIT, D. (ed.). Genders, Transgenders and Sexualities in Japan. New York:

Routledge, 2005.

MCLELLAND, M.; MACKIE, V. Routledge Handbook of Sexuality Studies in East Asia. New York: Routledge, 2015.

MIKU Symphony Kaito 15 ${ }^{\text {th }}$ Anniversary.MikuSymphony, [s. I.], [201-]. Disponivel em: http:// sp.wmg.jp/mikusymphony/. Acesso em: 5 jul. 2020.

MILLER, L.; BARDSLEY, J. (ed.). Bad Girls of Japan. New York: Palgrave Macmillan, 2005.

MOTTA, M.B.O saber como crime. In: MOTTA, M. B. (org.). Foucault, arte, epistemologia, filosofia e história da medicina, ditos e escritos. Rio de Janeiro: Forense Universitária, 2011. v. 7, p. 62-69.

NAGATOMO, S. Attunement through the body. New York: Suny Books, 1992.

N響と共演初音ミク・プロジェクションマッピング・椎名林檎. [S. I.: s. n.], 2016.1 vídeo (15 min). Publicado pelo canal yoshiyukirindoh. Disponivel em: https://www.youtube.com/watch?v=ogCuAbFvWbo. Acesso em: 8 jul. 2020.

PRECIADO, B. P. Manifesto Contrassexual: práticas subversivas de identidade. São Paulo: Ed. N-1, 2000.

PRESSE, F. O homem japonês que 'casou' com uma cantora de realidade virtual. G1, São Paulo, 11 nov.2018. Disponível em: https://g1.globo.com/economia/tecnologia/noticia/2018/11/12/ohomem-japones-que-casou-com-cantora-de-realidade-virtual.ghtml?fbclid=IwAR1Wokt4-JE ZRjtZgsZZFP2aRED7HPWwPJqaMNZQXWK81xNS4CLwhUNNwN. Acesso em: 14 jul. 2020.

ROBERTSON, J. T. Sexual Politics and Popular Culture in Modern Japan. Berkeley: University of California Press, 1998.

ROMANSKA, M. (ed.). The Routledge Compagnion to Dramaturgy. New York: Routledge, 2015.

SCHNEIDER, R. Performing Remains:art and War in Times of Theatrical Reenactment. New York: Taylor \& Francis, 2011.

SHIGEMATSU, S. Scream from the shadow, the women's liberation movement in Japan. Minnesota: University of Minnesota Press, 2012.

SONE, Y. Japanese Robot Culture: performance, imagination, and modernity. NewYork: Palgrave Macmillan, 2017.

SLAYMAKER, D. N. The Body in Postwar Japanese Fiction. Londres: Routledge Curzon, 2004.

SPIVAK, G. Pode o subalternofalar?. Belo Horizonte: EdUFMG, 2010.

STILL Be Here featuring Laurel Halo at The Barbican. Resident Advisor, [s. I.], 1 mar. 2017. Disponivel em: https://www.residentadvisor.net/reviews/20716. Acesso em: 1jul. 2020.

'STILL Be Here' with HatsuneMiku | Trailer. [S. I.: s. n.], 2016. 1 vídeo (1 min). Publicado pelo canal transmediale. Disponivel em: https://www.youtube.com/watch?v=ukkSHsRw104. Acesso em: 7 jul. 2020.

TAKEMURA, K. Feminist Studies/Activities in Japan: Present and Future. Lectora, Barcelona, v. 16, p. 13-33, 2010.

TSUJI, N. Lineage of Eccentrics. Tóquio: Kaikai Kiki Co, 2011. 
VON AUE, M. Tokyo men married videogame characters in VR. VOCATIV, [s. I.], 6 jul. 2017.

Disponível em: http://www.vocativ.com/439438/tokyo-japan-vr-wedding-hibiki-works/index.

html. Acesso em: 10 jul. 2020.

YUASA, Y. The Body, toward an Eastern Mind-Body Theory. New York: Suny Books, 1987.

Christine Greiner: é professora livre-docente do Departamento de Arte da PUC-SP e autora de diversos livros sobre corpo, cultura japonesa, filosofia política e arte.

Beatriz Yumı Aokı: é doutoranda e Mestre em Comunicação e Semiótica pela PUC-SP, bolsista Capes PROSUP. 